УДК 34.01

\author{
А. Г. Берестенников \\ Российская правовая акаделия Министерства юстищии РФ, \\ г. Иркутск, Российская Федераиия
}

\title{
СУЩНОСТЬ ПРИНЦИПОВ ПРАВА: ТЕОРЕТИЧЕСКИЕ ПРОБЛЕМЫ ПОНИМАНИЯ
}

\begin{abstract}
АНнотАция. Категория «принципы права» является актуальной для современной юридической науки, что характерно как для историко-теоретических, так и для отраслевых и межотраслевых дисциплин. Это, с одной стороны, обусловливает высокую степень разработанности данной темы, но, с другой стороны, создает значительное количество сложностей и противоречий на теоретическом уровне в понимании указанного правового феномена. Анализ современной юридической научной литературы свидетельствует об отсутствии единого подхода к пониманию принципов права, их философско-правовому обоснованию. В статье рассматривается многообразие подходов к пониманию принципов права, их соотношение с социально-политическими началами общества. Обобщаются методологические приемы, используемые при исследовании принципов права. Предлагается комплексный подход в теоретическом понимании принципов права, основанный на целях и задачах конкретного научного исследования.
\end{abstract}

кЛючЕВЫЕ словА. Принципы права; правовые принципы; правопонимание; формальное закрепление; социально-политические начала; функции науки; анализ; синтез.

ИНФОРМАЦИЯ О СТАТЬЕ. Дата поступления 25 марта 2015 г.; дата принятия к печати 26 июня 2015 г.; дата онлайн-размещения 31 мая 2016 г.

A. G. Berestennikov Russian Law Academy of RF Ministry of Justice, Irkutsk, Russian Federation

\section{ESSENCE OF PRINCIPLES OF LAW: THEORETICAL PROBLEMS OF THEIR COMPREHENSION}

ABSTRACT. The category of «principles of law» is topical for modern juridical science, which is characteristic both for historical and theoretical disciplines and for branch and inter-branch ones. This fact, on the one hand, determines a high level of development of the problem itgself but, on the other hand, creates a considerable number of difficulties and contradictions at the theoretical level in comprehending this legal phenomenon. Analysis of modern juridical scientific literature testifies shows absence of consistent approach to comprehending principles of law, their philosophic and legal substantiation. The article considers the variety of approaches to comprehending principles of law, their correlation with socio-political essence of society. It generalizes methodological techniques used in studying principles of law. It offers a complex approach to theoretical comprehension of principles of law based upon objectives and tasks of a specific research study.

KEYWORDS. Principles of law; legal principles; legal consciousness; formal entrenchment; socio-political essence; functions of science; analysis; synthesis.

ARTICLE INFO. Received March 25, 2015; accepted June 26 2015; available online May 31, 2016.

В современной юридической науке понятие «принципы права» является достаточно разработанным. Это характерно как для историко-теоретических, так и для отраслевых и межотраслевых юридических наук. Практически каждая научная работа, претендующая на универсальный охват, предваряется рассуждениями о собственных принципах. Такая тенденция свидетельствует о высокой степени акту-

(C) А. Г. Берестенников, 2016

\section{Baikal Research Journal}


альности рассматриваемого феномена для научного знания и не позволяет говорить о нем как о сугубо абстрактной конструкции, лишенной практической значимости.

Прежде чем перейти к рассмотрению проблематики, вынесенной в заглавие настоящей работы, необходимо определиться с понятием и сущностью принципов права, отразить их важные признаки и классификации, имеющие значение для данного исследования.

Начнем с того, что под принципом вообще принято понимать основное исходное положение какой-либо научной системы, теории, устройства и т. д. [1, с. 596]. В качестве ключевых слов, образующих «каркас» рассматриваемого понятия, можно назвать также основание, начало, исходное положение [2, с. 107]. В данном контексте названные слова являются синонимичными и по своим семантическим признакам восходят к латинскому корнеслову «рrincip», который, в свою очередь, обозначает нечто главное, ведущее [3, с. 960]. Юридическое понятие «принципы права» сохранило на себе указанный этимологический отпечаток, который отчетливо проявляется в нем с учетом предметной специфики.

Следует отметить, что юридическая наука, рассматривая указанное понятие, апеллирует к плюрализму мнений. Его основа - многообразие как отдельных научных концепций, так и целых правовых школ; его концентрированное выражение - дефиниции, которые можно встретить на страницах работ, посвященных названному вопросу. По этой причине представляется необходимым проанализировать некоторые понятия, выделить их существенные признаки, а также предметно рассмотреть сущность проблематики, связанной с формальным закреплением принципов в законодательстве, иных источниках права.

Следует начать с того, что советская правовая школа под принципами права традиционно понимает объективно обусловленные начала, руководящие идеи, отражающие развитие общества, а также становление и развитие самого права [4, с. 123]. Данное определение является классическим, поскольку содержит в себе все основные идеи, которые вкладывает в него современная наука. Вместе с тем рядом авторов не без основания подчеркивается, что указанное определение сформулировано в общем виде, т. е. без внимания к отдельным нюансам, которые, дополняя друг друга, складываются воедино и образуют общую научную картину, которая имеет право претендовать на полноту и достоверность. В этой перспективе подлинный интерес вызывают те исследования, которые предлагают иное определение принципам права.

Так, по мнению С. С. Алексеева, под принципами права следует понимать выраженные в нем исходные нормативно-руководящие начала [5, с. 98]; при этом надо понимать, что не всегда такие начала имеют свойство проявляться в конкретной норме-предписании - в ряде случаев принципы следуют из содержания комплекса правовых норм, которые регламентируют сходные общественные отношения. На системном уровне такая общность будет соответствовать институту права или отдельной отрасли.

Л. Д. Воеводин считает, что в самом общем виде принципы права можно охарактеризовать как закрепленные конституцией определяющие и руководящие идеи и установки, концентрированно выражающие ее содержание и учредительную природу [6, с. 32]. В целом, научная позиция данного автора сформулирована таким образом, что принципы права независимо от того, атрибутом какого уровня системы права они являются, должны быть закреплены в основном законе государства, либо в федеральных конституционных законах, либо в текущем законодательстве. Так или иначе, принципы права необходимо связаны с их выражением в правовой форме.

Ясно, что позиция Л. Д. Воеводина выражена, прежде всего, в конституционно-правовой плоскости, о чем свидетельствует привязка принципов права к содер-

\section{Baikal Research Journal}

электронный научный журнал Байкальского государственного университета 
жанию конституции. Вместе с тем такая специфика не отменяет теоретической ценности рассматриваемой позиции, которая четко определяет соотношение между формой и содержанием рассматриваемого правового феномена.

Заслуживает внимания позиция Р. Л. Иванова, согласно которой принципы права - закрепленные в различных источниках или выраженные в устойчивой юридической практике общепризнанные основополагающие идеи, адекватно отражающие уровень познания общесоциальных и специальных закономерностей права и служащих для создания внутренне согласованной и эффективной системы юридических норм, а также для непосредственного регулирования общественных отношений в случае пробельности [7, с. 118].

В соответствии с научными взглядами $\Gamma$. А. Кригера принципы права - это вытекающие из социально-экономической природы и закрепленные в праве идеологические и нравственные начала (руководящие идеи), направляющие регулятивную и охранительную функции права и определяющие характер, основания и объем государственного принуждения и иных мер воздействия, необходимых для обеспечения успешного развития господствующих общественных отношений [8, с. 102].

Следует подчеркнуть, что приведенная концепция излагается Г. А. Кригером в работе «Место принципов советского уголовного права в системе принципов права» . Этим объясняется ее привязка к методам регулирования, свойственным уголовному праву. Однако, несмотря на отраслевую специфику, надо руководствоваться замечанием, сопровождающим точку зрения Л. Д. Воеводина, и принимать во внимание «теоретический каркас» рассматриваемой концепции, согласно которому принципы права - закрепленные в нем идеологические и нравственные начала.

Проводя промежуточный итог, необходимо заключить, что изложенные концепции объединяет единый предикат, суть которого сводится к тому, что принципы права должны закрепляться либо находить свое выражение в законе либо в ином источнике права. Это ключевая идея, определяющая целое направление научной дискуссии. Значимость этой идеи обусловлена тем, что она выражает системные связи между принципами права, с одной стороны, и его источниками, с другой. Это в некоторой степени формирует оконченное представление о принципах права вообще, что делает указанную идею с научной точки зрения ценностно-ориентирующей.

Следует отметить, что позиция, согласно которой принципы необходимо должны быть закреплены в тех или иных источниках права, не претендует на научную монополию.

Так, по мнению И. Ф. Демидова, отдельные принципиальные идеи не находят своего закрепления в правовых нормах в виде специальных терминов и соответствующих формулировок. По этой причине принципы права не всегда стоит отождествлять с отдельными нормами. Более того, на общественные отношения, урегулированные нормами того или иного права, могут оказывать влияние и такие идеи-принципы, которые не закреплены в законе [9, с. 136].

Примечательной является позиция В. Н. Кудрявцева и С. Г. Келиной, согласно которой развитие системы права отнюдь не начинается в формулирования ее принципов. Новая общественно-экономическая формация ставит перед складывающимися правовыми институтами и нормами весьма практические задачи. Однако в ходе их стабилизации и оформления складываются те принципы, которые характерны для общественной системы [10, с. 24]. По мнению указанных авторов, принципы права не всегда находят свое отражение в законодательстве либо иных источниках права. В таких случаях наличие соответствующих принципов предшествует процедуре их формального закрепления; при этом сам факт их закрепления концептуально не меняет степень регулятивного воздействия принципов права на общественные отношения.

\section{Baikal Research Journal}

электронный научный журнал Байкальского государственного университета 
Анализируя указанные точки зрения, заметим, что в научной среде они вызывают ощутимый резонанс. Так, ряд авторов вполне справедливо предостерегают от отождествления принципов права, закрепленных в действующем законодательстве, с научными идеями, сформулированными учеными в рамках решения тех или иных практических задач. В противном случае, по их мнению, такое отождествление приведет к искажению регулятивной роли принципов права, которая является своего рода демаркационной линией между такими принципами и научными идеями [11, с. 93].

Однако приведенное замечание является только одним аспектом сложной проблемы. Бесспорно, что значение фундаментальной науки в деле осмысления правовой материи представляется немалым, но в данном случае было бы явно некорректно сводить точки зрения В. Н. Кудрявцева, С. Г. Келиной и И. Ф. Демидова лишь к тому, что принципы права, будучи не закрепленными в законе, представляют собой некие исходные положения, сформулированные наукой. Такой вывод являлся бы слишком узким и несправедливым по отношению к названным авторам.

Очевидно следующее: если признавать за принципами права реальное регулятивное воздействие на те или иные общественные отношения и в то же время допускать, что такие принципы могут не находить формального закрепления в действующем законодательстве (либо иных источниках права), означает утверждать, что принципы права представляют собой не только правовую, но и мировоззренческую категорию. Рассуждая в таком ключе, добавим, что в данном случае принципы права также будут обусловлены общественными отношениями, в которых они зародились, носить отвлеченный характер и обнаруживать особенность к опережению во времени факт своего закрепления в той или иной правовой норме [12, с. 26].

Изложенное подчеркивает, что принципы права сначала проявляются в реальной жизни и только затем, материализованные в отдельных институтах и их нормах, находят формальное закрепление в источниках права.

Таким образом, в части проблемы формального закрепления принципов права при первом приближении в науке можно обнаружить явную оппозицию: одна группа авторов считает, что принципы права в обязательном порядкеподлежат подобному закреплению, другая группа допускает, что такое закрепление возможно, не всегда необходимо.

Думается, что ключевая проблема, которая определяет полярные стороны названной дискуссии, кроется в правопонимании. В частности, первая группа авторов, отстаивающая необходимость формального закрепления принципов права, исходит из позитивистского понимания как самого права, так и его принципов. Право в данном случае рассматривается в чистом виде как система норм, установленных либо санкционированных государством, при этом общественные отношения (в том числе юридическая практика), влияющие на указанные факторы, принципиально во внимание не принимаются [13, с. 28; 14, с. 321]. Лаконично этот подход выражает известная формула римского права: quod non est in actis, non est in mundo (чего нет в документах, того нет в природе).

Вторая концепция, наоборот, исходит из непозитивистского, т. е. более широкого понимания права, и потому рассматривает его в тесной взаимосвязи с общественными отношениями, которые являются его субстратом [15, с. 109]. Другими словами, право (естественное право) формируется независимо от государства и обладает приоритетом по отношению к закону [13, с. 28]. Ценность этой концепции заключается в том, что она обнажает динамическую сторону права, что подводит к необходимости рассматривать его не только в статике, но и диалектически - от зарождения к развитию и от развития к угасанию.

\section{Baikal Research Journal}


Поскольку принципы права являются его атрибутами, то логично, что сказанное о праве справедливо и для его принципов. Таким образом, принципы права можно рассматривать либо только на стадии, когда они формально закреплены, либо на более ранних этапах, когда общественные отношения всути своей такие принципы создали и законодателю осталась их только сформулировать в виде определенной правовой нормы.

Как известно, проблема правопонимания лежит в плоскости профессиональноидеологических предпочтений того или иного автора, — это объясняет тот плюрализм позиций относительно сущности права, который предлагает современная наука. Невозможность свести такое многообразие к определенной монистической концепции свидетельствует об отсутствии строгих критериев того, что в данном случае считать истинным, а что ложным. В этой связи представляется, что аналогичное заключение справедливо для принципов права - как их определять, в широком или узком смысле, всецело зависит от научных предпочтений, а также цели научного исследования и потому не может лежать в пределах оценок «корректно» или «некорректно». Более того, рассуждая в этом же русле, следует обратить внимание на формулировки, которые используют авторы, точки зрения которых уже приведены.

Так, к примеру, С. С. Алексеев не ведет речь исключительно о формальном закреплении принципов права в законодательстве, как это делают Г. А. Кригер или Л. Д. Воеводин - он указывает на возможность таких принципов находить свое выражение в законодательстве, что, согласимся, делает его дефиницию значительно более гибкой. В самом деле, если вести речь именно о формальном закреплении принципов права в законодательстве, то под этим следует понимать ту ситуацию, когда тот или иной принцип прямо выражен в источнике права в качестве такового (к примеру, принцип справедливости в ст. 6 Уголовного кодекса РФ от 13 июня 1996 года № 61-ФЗ). Иными словами, когда содержание того или иного принципа права косвенно вытекает из совокупности однородных правовых норм, но прямо не следует из конкретной нормы, при всей логичности и очевидности, такой случай не может говорить именно о формальным закреплении соответствующего принципа.

Это важный момент, наличие которого делает и сложным, и актуальным затронутый вопрос. Отсюда становится понятным, что проблема закрепления принципов права в законодательстве, иных источниках права в науке решается трояко: через формальное закрепление, когда принцип непосредственно выражен в качестве отдельной правовой нормы, через следование из совокупности однородных норм, наконец, через следование из сущности сложившихся общественных отношений. В данном случае четко прослеживается восхождение от частного к общему по содержанию и нисхождение от неопределенного к определенному по форме. В этой связи два направления рассматриваемой дискуссии, по нашему мнению, являются вовсе не оппозицией, а проявлениями единого протяженного во времени диалектического процесса по созданию правовой формы. Изначально предпосылки принципов права закладываются в общественных отношениях, затем отдельные отрасли права и их институты косвенно формируют собственные принципы, затем эти принципы закрепляются в качестве отдельных правовых норм.

В связи с изложенным заметим, что проблема формального закрепления связана с другой, родственной ею проблемой, рассмотрение которой помогает проявить сущность принципов права как самостоятельных юридико-философских категорий.

Так, в науке подчеркивается различие, на первый взгляд, двух тождественных понятий: принципов права и правовых принципов [16, с. 20].

Ряд авторов считают, что указанные понятия некорректно употреблять как синонимичные. По их мнению, правовые принципы представляют собой категории

\section{Baikal Research Journal}


правового сознания, то есть идеи, влияющие на восприятие, усвоение и реализацию норм субъектами правоотношений. Таким образом, в данном контексте правовые принципы рассматриваются в качестве мировоззренческих ориентиров, связанных с правом и его проявлениями [17, с. 15]. Принципы права, в свою очередь, объединяются в более узкую категорию, видовым отличием которой является то, что последние не только представляют собой мировоззренческие ориентиры, но и находят отражение в тех или иных источниках права. Справедливо в данном контексте звучит позиция А. Н. Попова, согласно которой принципы права и принципы правосознания (правовые принципы) с момента появления права могут существовать параллельно; вместе с тем принципы права составляют часть правовой материи, неразрывны с содержанием и формой права [18, с. 26]. В этой связи следует сделать такой вывод: всякие принципы права являются правовыми принципами, но не всякие правовые принципы являются принципами права. При этом данные понятия могут частично совпадать, примером чего может служить упомянутый ранее принцип справедливости, закрепленный в ст. 6 Уголовного кодекса РФ, и так называемый «индекс защищенности», выводимый на основе сугубо доктринальных понятий о справедливости уголовного закона [19, с. 25].

Представляется, что указанная дифференциация понятий является и обоснованной, и необходимой. Применительно к принципам права введение категории «правовые принципы» позволяет рассмотреть первые не только с позиции «чистого» права, но и во взаимосвязи с общественными отношениями, определить предпосылки к их оформлению, а также последствия такого действия для процесса реализации правовых норм.

Немаловажным моментом, на который также следует обратить внимание, является еще и то, что разведение элементов правовой материи и правого сознания позволяет в комплексе рассмотреть проблематику, связанную с предметом настоящего исследования, а именно что понимать под принципами права. Думается, что данная онтологическая проблема имеет в науке еще одно измерение, третье по счету.

В частности, рассматривая принципы права, ряд авторов обращает внимание на социально-политическую подоплеку данного феномена [16, с. 19]. Логика здесь довольно очевидна: принципы права суть правовые принципы, правовые принципы как элементы правового сознания суть производные общественных отношений. Проблема взаимосвязи принципов права и общественных отношений (социально-политических основ) решается, по большому счету, двояко: либо посредством их тождества, либо посредством различия. Рассмотрим данные позиции более подробно.

Говоря о тожестве принципов права и социально-политических основ того или иного общества, некоторые авторы исходят из того, что принципы права нельзя рассматривать изолированно, т. е. в отрыве от реальной действительности. В случае использования такого подхода необоснованно сужается предмет исследования: изучение права во взаимосвязи с общественными отношениями подменятся изучением системы правовых предписаний. Это не позволяет рассмотреть право комплексно и противоречит философским основам научной методологии [20, с. 15-16].

Как известно, сущность и ее проявления, характерные для целого, характерны для ее части. В этой связи очевидно, что принципы права являются частной рефлексией основных начал, свойственных социальной системе. Следовательно, принципы права и принципы построения социальной системы обусловлены одними и теми же универсальными законами, трансформации которых определяют характер и сущность социальной системы и ее атрибутов. Пренебрежение этими обстоятельствами препятствует рассмотрению права в его генезисе, безосновательно исключит из видения факторы, лежащие вне права, воздействуя на

\section{Baikal Research Journal}

электронный научный журнал Байкальского государственного университета 
которые, можно добиваться учреждения новых и эффективной коррекции действующих правовых инструментов.

Другая концепция, основанная на различении принципов права и социально-политических основ общества, зиждется на той аргументации, согласно которой объединение указанных категорий в единое целое создает опасность для выведения принципов права «из самих себя». Иными словами, в рамках этой концепции принципы права растворятся в более широкой категории, что не позволит увидеть их специфику и юридико-технические особенности. Довольно точно эту позицию иллюстрирует мнение Р. Л. Иванова, в соответствии с которым руководящие положения социально-политического характера целесообразно рассматривать не как принципы права, а как принципы, действующие в правовой сфере, поскольку они не дают ответа на вопрос, каким образом налажена система правового регулирования, следовательно, лишены ключевого признака - правовой формы [21, с. 47].

При всей противоположности приведенных аргументов все же думается, что обе концепции имеют свои достоинства и потому должны рассматриваться не как взаимоисключающие, а как сосуществующие. Известное правило формальной логики, что из двух противоположных суждений одно истинно, второе ложно, третьего не дано, к данному случаю не вполне применимо, поскольку указанные точки зрения соответствуют аналитической и синтетической функциям научного знания. Эти функции - важнейшие составляющие научной методологии.

Как известно, главная задача анализа сводится к разложению целого на части. Целью данной операции является детальное изучение мелких составляющих более крупного объекта или процесса [22, с. 58]. В этой связи в конструкцию анализа изначально закладывается некоторая ограниченность, которая заключается в намеренном выведении предмета исследования из общего информационного контекста с последующим всесторонним рассмотрением. Задача синтеза прямо противоположна - она представляет собой процесс соединения или объединения ранее разрозненных частей в единое целое. На когнитивном уровне синтетическая работа сводится к созданию единой картины окружающей действительности либо его отдельной части $[17$, с. 1205$]$.

Очевидно, что первым достоинством анализа является конкретика, первым недостатком - концептуальность. Для синтеза, в свою очередь, характерен прямо противоположный тезис. Проецируя эти соображения на приведенные точки зрения относительно социально-политической природы принципов права, отметим, что отождествление последних с социально-политическими основами является проявлением синтетической функции научного знания. Такой подход в особенности применим для философии права, а также государственно-правовых дисциплин, которые претендуют на системное осмысление права в контексте других социальных феноменов (политики, экономики, религии, культуры, науки и т. д.).

В свою очередь, подход, согласно которому принципы права рассматриваются как категория, хоть и имеющая социально-политическую основу, но все же носящая самостоятельный характер, основанный на закреплении в действующем законодательстве (либо иных источниках права), следует рассматривать в качестве порождения аналитической составляющей научного знания. Отсюда следует, что описанная концепция наиболее пригодна для отраслевых юридических дисциплин, цель которых - выработка конкретных инструментов для регулирования определенной сферы общественных отношений. В рамках достижения этих целей необходимо мыслить определенными («вещественными») категориями, связанными, прежде всего, с юридико-техническими особенностями оформления правового материала. Напротив, оперирование общими схемами, свойственными философским

\section{Baikal Research Journal}


и государственно-правовым дисциплинам, здесь не вполне пригодно, поскольку такая работа не дает ответа на главный вопрос - вопрос о правой форме, на который справедливо обращает внимание Р. Л. Иванов [21, с. 43].

Коротко говоря, разрешение проблемы тождества либо разведения принципов права и социально-политических основ того или иного общества носит выражено релятивистский характер, поскольку зависит от целей и задач научного исследования, посвященного такой проблеме. В частности, если целью научного исследования является построение общей картины некоторой правой системы, то, безусловно, если не тождество, то максимально возможное сближение принципов права и социально-политических основ общества видится абсолютно необходимым методологическим приемом, использование которого позволяет проследить тенденции развития указанной системы. Напротив, исследования, носящие узкоспециальный характер и потому отвечающие преимущественно на вопрос о правой форме, должны строиться исходя из различия двух рассматриваемых категорий.

Таким образом, проблематика, связанная с формальным закреплением принципов права, их сопоставлением с правыми принципами, а также с социально-политическими основами такого или иного общества, имеет родственное происхождение. Суть в том, что принципы права могут рассматриваться в широком либо в узком смысле; это, в свою очередь, определяется характером научного исследования, которое соответственно может носить преимущественно синтетический либо преимущественно аналитический характер.

По большому счету, логика приведенных рассуждений склоняет к объединению указанных концепций в рамках одного научного исследования. Так, по мнению В. В. Мальцева, система принципов права должна отражать как минимум три уровня: отрасли права, отрасли законодательства, а также их отдельных категорий и институтов [23, с. 238]. Эта система существует лишь в связи с предметом определенной отрасли права, ибо в противном случае такие принципы не будут обладать собственным правовым содержанием и, значит, попросту не будут иметь прямого отношения к предмету такой отрасли. Вместе с тем, поскольку система принципов права входит в структуру общественного и правового сознания, ее схема должна отражать не только внутреннюю структуру и содержание этих принципов, но и внешние связи между ними и указанными формами общественного сознания.

Представляется, что В. В. Мальцев скорее говорит о таком методологически выверенном исследовании, в котором «аналитики» ровно столько, сколько «синтетики». На практике этого добиться чрезвычайно трудно - не случайно данный автор впоследствии приходит к выводу о том, что в новейшей юридической литературе исследование принципов права через призму указанных аспектов фактически не проводится.

Не оспаривая программного характера позиции В. В. Мальцева, все же отметим, что в каждом научном исследовании акценты расставлены всегда индивидуально, что в реальности будет «выводить его из методологического равновесия» в угоду определенным целям и задачам. Думается, что это не является логической ошибкой, а свидетельствует о разумном утилитаризме автора. Это справедливо как для неопределенного круга правовых проблем, так и предметно для принципов права.

Таким образом, проблемы формального закрепления принципов права и их отождествления с социально-политическими основами общества могут и должны разрешаться двояко. Первый подход, предполагающий обязательность формального закрепления таких принципов и их отдельное рассмотрение от социально-политических основ, наиболее пригоден в рамках узкоотраслевых исследований: в этом случае акцент делается на правовой форме, общественные отношения рас-

\section{Baikal Research Journal}

электронный научный журнал Байкальского государственного университета 
сматриваются как менее значимый фактор. Второй подход, напротив, допускает отсутствие формального закрепления принципов и их отождествление с социально-политическими основами, что делает такой подход наиболее пригодным для историко-теоретического дискурса: в этом случае акцент делается на взаимосвязи принципов права и общественных отношений, вопрос правовой формы рассматривается как второстепенный. Представляется, что оба подхода имеют право на существование и должны рассматриваться не как взаимоисключающие, а как сосуществующие научно-методологические концепции, применяемые при исследованиях принципов права.

\section{Список использованной литературы}

1. Ожегов С. И. Толковый словарь русского языка / С. И. Ожегов, Н. Ю. Шведова. - М. : Азбуковник, 2000. - 736 с.

2. Рыбинская Е. Т. О понятии принципов уголовного процесса / Е. Т. Рыбинская // Известия Иркутской государственной экономической академии. -2012 . - № 6 (86). - С. 107-111.

3. Большой энциклопедический словарь / под ред. А. М. Прохорова. -2-е изд., перераб. и доп. - М. : СПб. : Больш. Рос. энцикл. : Норинт, 1997. - 1456 с.

4. Общая теория права и государства. Академический курс / под ред. М. Н. Марченко. М. : Зерцало, 1998. - 720 с.

5. Алексеев С. С. Общая теория права : в 2 т. / С. С. Алексеев. - М. : Юрид. лит., 1981. T. 1. $-360 \mathrm{c}$.

6. Воеводин Л. Д. Юридический статус личности в России : учеб. пособие / Л. Д. Воеводин. - М. : Изд-во Моск. ун-та : Норма : Инфра-М, 1997. - 304 с.

7. Иванов Р. Л. О понятии принципов права / Р. Л. Иванов // Вестник Омского университета. - 1996. - Вып. 2. - С. 115-118.

8. Кригер Г. А. Место принципов советского уголовного права в системе принципов права / Г. А. Кригер // Советское государство и право. - 1981. - № 2. - С. 102-107.

9. Курс советского уголовного процесса. Общая часть / под ред. А. Д. Бойкова, И. И. Карпеца. - М. : Юрид. лит., 1989. - 424 с.

10. Келина С. Г. Принципы советского уголовного права / С. Г. Келина, В. Н. Кудрявцев. - М. : Наука, 1988. - 176 с.

11. Зажицкий В. И. Правовые принципы в законодательстве РФ / В. И. Зажицкий // Государство и право. $-1996 .-$ № 11. - С. 93-95.

12. Семенова И. С. Принцип равенства перед законом в уголовном праве Российской Федерации : дис. ... канд. юрид. наук : 12.00 .08 / И. С. Семенова. - Саратов, 2004. - 184 с.

13. Нерсесянц В. С. Общая теория права и государства : учебник / В. С. Нерсесянц. - М. : Норма, 2001. $-552 \mathrm{c}$.

14. Рыбинская Е. Т. Принципы уголовного судопроизводства (понятие и правая природа) / Е. Т. Рыбинская // Проблемы современного российского законодательства : материалы I Всерос. науч.-практ. конф. Иркутск, 18 окт. 2012 г. : в 2 ч. - М. ; Иркутск : Рос. правовая акад. Минюста России, 2012. - Ч. 1. - С. 317-322.

15. Кешикова Н. В. Принципы права в свете постклассической юридической рациональности / Н. В. Кешикова // Известия Иркутской государственной экономической академии. - 2012. - № 5 (85). - С. 109-115.

16. Кораблев Р. Н. Принцип законности и его реализации в уголовном праве Российской Федерации : дис. ... канд. юрид. наук : 12.00 .08 / Р. Н. Кораблев. - М., 2004. - 202 с.

17. Сабанин С. Н. Справедливость освобождения от уголовного наказания / С. Н. Сабанин. - Екатеринбург : Высш. шк. МВД Рос. Федерации, 1993. - 262 с.

18. Попов А. Н. Принцип справедливости в уголовном праве : дис. ... канд. юрид. наук : 12.00.08 / А. Н. Попов. - СПб., 1993. - 145 с.

19. Минникес И. А. «Индекс защищенности» и его роль в совершенствовании законодательства и защите прав человека [Электронный ресурс] / И. А. Минникес // Известия Иркутской государственной экономической академии (Байкальский государственный университет экономики и права). - 2013. - № 4. - Режим доступа : http://brj-bguep.ru/reader/article. $\operatorname{aspx} ? \mathrm{id}=18431$.

\section{Baikal Research Journal}


20. Бороноев А. О. Конкретно-исторический поход в социальном исследовании / А. О. Бороноев, А. Е. Бовкалов // Роль научных принципов и понятий в социальном исследовании / под ред. Г. А. Подкорытова. - Л. : Изд-во Ленингр. ун-та, 1976. - 148 с.

21. Иванов Р. Л. Принципы советского права : дис. ... канд. юрид. наук : 12.00.01/ Р. Л. Иванов. - Л., 1988. - 218 с.

22. Популярный энциклопедический словарь / под ред. М. С. Гилярова. - М. : РИПОЛ-классик, 1999. - 1632 с.

23. Энциклопедия уголовного права : в 2 т. / Ю. Е. Пудовочкин, В. В. Мальцев, Н. Н. Пикуров, Б. В. Волженкин. - СПб. : Изд. проф. Малинина, 2005. - Т. 1 : Понятие уголовного права. - $695 \mathrm{c}$.

\section{References}

1. Ozhegov S. I., Shvedova N. Yu. (eds). Tolkovyy slovar' russkogo yazyka [Definition Dictionary of the Russian Language]. Moscow, Azbukovnik Publ., 2000. 736 p.

2. Rybinskaya E. T. On concept of principles of criminal procedure. Izvestiya Irkutskoy gosudarstvennoy ekonomicheskoy akademii = Bulletin of Irkutsk State Economics Academy, 2012, no. 6 (86), pp. 107-111. (In Russian).

3. Prokhorov A. M. (ed.). Bolshoi entsiklopedicheskii slovar [Big Encyclopedic Dictionary]. $2^{\text {nd }}$ ed. Moscow, Saint Petersburg, Bolshaya Rossiiskaya entsiklopediya Publ., Norint Publ., 1997. $1456 \mathrm{p}$.

4. Marchenko M. N. (ed.). Obshchaya teoriya prava i gosudarstva. Akademicheskii kurs [General Theory of Law and State. An Academic course]. Moscow, Zertsalo Publ., 1998. 720 p.

5. Alekseyev S. S. Obshchaya teoriya prava [General Theory of Law]. Moscow, Yuridicheskaya Literature Publ., 1981. Vol. 1. 360 p.

6. Voyevodin L. D. Yuridicheskii status lichnosti $v$ Rossii [Legal status of personality in Russia]. Moscow, Lomonosov Moscow State University Publ., Norma Publ., Infra-M Publ., 1997. 304 p.

7. Ivanov R. L. On concept of principles of law. Vestnik Omskogo universiteta $=$ Bulletin of Omsk University, 1996, iss. 2, pp. 115-118. (In Russian).

8. Kriger G. A. Place of principles of Soviet criminal law in the system of principles of law. Sovetskoe gosudarstvo i pravo = Soviet State and Law, 1981, no. 2, pp. 102-107. (In Russian).

9. Boikov A. D., Karpets I. I. (eds). Kurs sovetskogo ugolovnogo protsessa. Obshchaya chast' [A Course of Soviet Criminal Procedure. General Part]. Moscow, Yuridicheskaya Literature Publ., 1989. 640 p.

10. Kelina S. G., Kudryavtsev V. N. Printsipy sovetskogo ugolovnogo prava [Principles of Soviet criminal law]. Moscow, Nauka Publ., 1988. 176 p.

11. Zazhitskii V. I. Legal principles in RF legislation. Gosudarstvo i pravo = State and Law, 1996, no. 11, pp. 93-95. (In Russian).

12. Semenova I. S. Printsip ravenstva pered zakonom v ugolovnom prave Rossiiskoi Federatsii. Kand. Diss. [Principle of equality before the law in criminal law of the Russian Federation. Cand. Diss.]. Saratov, 2004. 184 p.

13. Nersesyants V. S. Obshchaya teoriya prava $i$ gosudarstva [General Theory of Law and State]. Moscow, Norma Publ., 2001. 552 p.

14. Rybinskaya E. T. Principles of criminal procedure (concept and legal nature). Problemy sovremennogo rossiiskogo zakonodatel'stva. Materialy I Vserossiiskoi nauchno-prakticheskoi konferentsii. Irkutsk, 18 oktyabrya $2012 \mathrm{~g}$. [Problems of modern Russian legislation. Materials of the $5^{\text {th }}$ All-Russian Research Conference, Irkutsk, October 18, 2012]. Moscow, Irkutsk, Russian Law Academy of RF Ministry of Justice, 2012, pr. 1, pp. 317-322. (In Russian).

15. Keshikova N. V. Principles of law in the context of post-nonclassical legal rationality. Izvestiya Irkutskoy gosudarstvennoy ekonomicheskoy akademii = Bulletin of State Economics Academy, 2012, no. 5 (85), pp. 109-115. (In Russian).

16. Korablev R. N. Printsip zakonnosti i ego realizatsii v ugolovnom prave Rossiiskoi Federatsii. Kand. Diss. [Principle of legality and its implementation in criminal law of the Russian Federation. Cand. Diss.]. Moscow, 2004. 202 p.

17. Sabanin S. N. Spravedlivost' osvobozhdeniya ot ugolovnogo nakazaniya [Justice of relief from criminal punishment]. Petersburg, Higher School of RF MIA Publ., 1993. 262 p.

18. Popov A. N. Printsip spravedlivostiv ugolovnom prave. Kand. Diss. [Principle of justice in criminal law. Cand. Diss.]. Saint Petersburg, 1993. 145 p.

\section{Baikal Research Journal}


19. Minnikes A. I. «Index of degree of protection» and its role in improving legislation and protection of human rights. Izvestiya Irkutskoy gosudarstvennoy ekonomicheskoy akademii (Baykalskiy gosudarstvennyy universitet ekonomiki $i$ prava) = Bulletin of Irkutsk State Economics Academy (Baikal State University of Economics and Law), 2013, no. 4. Available at: http:// brj-bguep.ru/reader/article.aspx?id=18431. (In Russian).

20. Boronoyev A. O., Bovkalov A. E. Concrete and historical approach social research. In Podkorytov G. A. (ed.). Rol' nauchnykh printsipov i ponyatii v sotsial'nom issledovanii [Role of scientific principles and concepts in social research]. Leningrad University Publ., 1976. 148 p.

21. Ivanov R. L. Printsipy sovetskogo prava. Kand. Diss. [Principles of Soviet law. Cand. Diss.]. Leningrad, 1988. 218 p.

22. Gilyarov M. S. (ed.). Populyarnyi entsiklopedicheskii slovar [Popular Encyclopedic Dictionary]. Moscow, RIPOL-klassik Publ., 1999. 1632 p.

23. Pudovochkin Yu. E., Maltsev V. V., Pikurov N. N., Volzhenkin B. V. Entsiklopediya ugolovnogo prava [Encyclopedia of Criminal Law]. Saint Petersburg, Prof. Malinin Publ., 2005. Vol. $1.695 \mathrm{p}$.

\section{Информация об авторе}

Берестенников Алексей Геннадьевич - аспирант, кафедра теории и истории государства и права, Иркутский юридический институт (филиал), Российская правовая академия Министерства юстиции РФ, 664011, г. Иркутск, ул. Некрасова, 4, e-mail: Alex-Blitz@yandex.ru.

\section{Author}

Alexey G. Berestennikov - PhD Student, Chair of of Theory and History of State and Law, Irkutsk Judicial Institute (branch), Russian Law Academy of RF Ministry of Justice, 4 Nekrasov St., 664011, Irkutsk, e-mail: Alex-Blitz@yandex.ru.

\section{Библиографическое описание статьи}

Берестенников А. Г. Сущность принципов права: теоретические проблемы понимания / А. Г. Берестенников // Baikal Research Journal. — 2016. — T. 7, № 3. — DOI : 10.17150/2411$\underline{6262.2016 .7(3) .25 .}$

\section{Reference to article}

Berestennikov A. G. Essence of principles of law: theoretical problems of their comprehension. Baikal Research Journal, 2016, vol. 7, no. 3. DOI : 10.17150/2411-6262.2016.7(3).25. (In Russian).

\section{Baikal Research Journal}

